\title{
Spatial Distribution of Ancylostomiasis in Soil of Slums of Northren Lahore
}

\author{
Shahida Azhar Ali ${ }^{1}$, Tanveer Akhtar ${ }^{2}$, Khalid Mahmood $^{3}$, Wajid Ali Safi ${ }^{4}$, \\ 1 \& 2 Department of Zoology, University of the Punjab, Quaid-e-Azam Campus, Lahore, Pakistan \\ ${ }^{3}$ Department of Space Sciences, University of the Punjab, Quaid-e-Azam Campus, Lahore, Pakistan \\ ${ }^{4}$ Solid Waste Management, Lahore, Pakistan
}

\section{Part of Ph.D. thesis of first author}

Abstract: A study was launched in slums of Lahore, Punjab from Nov 2006 to Oct 2008. Thematic disease map showed $3.22 \%$ prevalence of Ancylostoma caninum (A.caninum) in contaminated soil samples collected from slums of Lahore. Area wise the highest prevalence of A. caninum's eggs shed by dogs in contaminated soil samples of slums was observed $5 \%$ in Missri Shah followed by $4.67 \%$ in Bhutto Colony $3.83 \%$ in Siddiqia Colony, 2.83 \% in Khairdin Park, 2 \% in Sheikhupura Road and lowest 1 \% in Scheme No 2espectively. The highest month wise prevalence $10.67 \%$ was observed in October that gradually declined $0.67 \%$ in March. The overall prevalence ratio of ancylostomiasis was (3.22 \%). Thematic Disease map showed spatial prevalence.

Keyword: Slums, Pakistan, Prevalence, ancylostomiasis, Ancylostoma caninum.

\section{Objective}

To observe the spatial distribution of A.caninum and to assess the degree of prevalence (\%) in soil being contaminated by faeces of pet / stray dogs in slums of Lahore.

\section{Introduction And Literature Review}

Ancylostomiaisis is a widely spread parasitic disease in dogs / cats, in tropical and subtropical areas (Loukas et al. 2006) cause by Ancylostoma caninum (A.caninum) (Umar, 2009). It is the most common parasite of dog (Bojar and Klapec, 2012) with cosmopolitan distribution (Sowemimo and Asaolu, 2008 ), exists as zoonotic agent (Edosomwan and Chinweuba, 2012) that constitute a significant risk for public health (Kollataj et al., 2012). Ancylostomiaisis is also a soil transmitted disease usually known as sapro zoonosis i.e. infected eggs spread in soil, on vegetables, raw fruits and herbs (Jaffry et al. 2009). A. caninum is very pathogenic to stray dog (Ashraf et al., 2008) than domestic (Umar, 2009) because it's infective filarial larvae from soil can penetrate into skin of dog cause lesion, wet eczema that is very severe to dog.

\section{Importance Of A. caninum In Dog}

A.caninum causes hemorrhagic dirrahoea (Lamb et al. 2012), atrophy of intestinal villi, eczema especially in rainy season when they get their feet be wet (Ashraf et al. 2008) anemia (Loukas and Prociv, 2001) and eosinophila $10 \%$ to $15 \%$ less than man (Bhatti et al. 2009; Ngui et al. 2012).

\section{Life Cycle In Dog}

A. caninum lives in small intestine of dog (Ashraf et al. 2008), female lays 16,000 eggs / day, eliminate via faeces in environment, contaminate the soil, vegetables, fruits, and herbs (Khayatnouri and Garedaghi, 2012). Eggs can survive at temperature between $25^{\circ} \mathrm{C}$ to $30^{\circ} \mathrm{C}$, humidity above $90 \%$, under shade, availability of $\mathrm{O}_{2}$ and change into $1^{\text {st }}$ stage larva, after one week molts into $3^{\text {rd }}$ stage larva. This is infective not only to definite host (pups) itself but also for human, live in soil for further 3 week. It can now enter to pups via oral route as they ingest contaminated soil or via penetration of skin, cause skin lesions and through blood stream lodge into small intestine as $4^{\text {th }}$ stage larva and after maturity again the cycle is repeated. It causes eosinophilic enteritis in dogs restricted to small intestine, treatable but recurrent with seasonal changing pattern. 20 days after post infection low level of $\mathrm{Hb}$ was observed in dogs due to low iron diet (Held et al. 2006). The juvenile larvae transfer to pups via transmammary / transplacental transmission (Edosomwan and Chinweuba, 2012).

After examining faecal samples of dogs the prevalence rate $13.4 \%$ for A. caninum and $2.5 \%$ for $T$. canis was obsereved (Isabel et al. 2005), whereas in Mashad out of 100 stray dogs $91 \%$ were found naturally infected, having $1 \%$ infection of A. caninum and $37 \%$ T. canis (Razmi et al. 2006). Out of 203 faecal samples of dogs $59.1 \%$ were positive for A. caninum, stray dogs showed prevalence rate $72.7 \%$ and pet $54 \%$ due to the fact that pet were living in proper situations and were provided balance food as compared to stray dogs (Ashraf, 
et al. 2008). In Argentina in2004 393 dog's faecal samples were observed for the presence of T. canis, 114 (29.0\%) samples were infested with A. caninum eggs, out of them and $53 \%$ eggs were found in urban slums areas with low SES (Martin and Demonte, 2008). Freshly collected and examined faecal material of dogs showed high prevalence as compared to the frozen one (Cringoli et al. 2011). In the case of the nematodes, A.caninum had a high prevalence (35.71\%) (Ugwoke et al. 2011). In Malaysia 221 faecal samples of dogs were examined, $48 \%$ were found positive for A.caninum infestation, $71.4 \%$ rural stray dogs and $48 \%$ in urban were naturally infected (Mahdy et al. 2012).

Soil samples were the tools to determine the prevalence / infection ratio in respect to the inhabitants from where these samples were taken and also depicted the type of infestation of infected and carrier man / dog or other pets. Soil contamination was being increased due to popular fashion to keep dog as a pet (Avcioglu and Balkaya, 2011). Ova of helminth deposited in soil, hibernated and the infective form harmed the person came in direct contact with that contaminated soil, eggs might be transferred from soil to vegetables, fruits, insects, animals and man. Level of soil contamination had been determined by level of contamination of parks, public playgrounds and soil of the surroundings being contaminated by stray or pet dogs (Kurnosov, 2009) that in turn depicted the type and degree of prevalence / infection being prevailed in the inhabitant and stray or pet dogs. In Wrolawski, Poland out of 185 soil samples $20 \%$ were positive, out of them $3.2 \%$ prevalence was for T. canis and A. caninum (4.9\%) respectively (Perec-Matysiak et al. 2008). Whereas in Nigeria, 608 soil samples were examined and overall prevalence was $62 \%$, out of it $7.2 \%$ were positive for A. lumbricoides, $3.7 \%$ for $T$.

trichiura, $50.4 \%$ T. canis, $9.0 \%$ A. caninum and $3.9 \%$ for E. granulosus (Maikai et al. 2008). In Poland 215 soil samples were collected from beech areas and playgrounds, $18.6 \%$ samples were found positive for A. caninum eggs (Bojar and Kłapeć, 2012).

\subsection{Collection Of Specimens From The Soil}

\section{Material And Methods}

To record the prevalence of ova of zoonotic parasites and soil transmitted helminthes (STHs), 3600 soil samples (25 / locality / month) were collected from 6 different localities i.e. 6 slums (Bhutto Colony, Siddiqia Colony, Scheme No 2, Sheikhupura Road, Khairdin Park and Missrisha) of Lahore, Punjab, Pakistan from November 2006 to October 2008. Soil was collected from five different depths of the same spot i.e. from the playgrounds, public parks, fields, filth depose and near the dunghills. Samples were immediately transferred to the Parasitology Laboratory, University of the Punjab, Lahore, Pakistan. Soil was kept in screw caped plastic vials clearly labeled with date and place of collection. For the presence of helminth's eggs these samples were examined on the same day by Sodium hypochlorite recovery technique (WHO, 1991 and Urquhart et al. 2001) and by Damp pad technique to identify ova (Seppo et al. 2002).

\section{Sodium Hypochlorite Technique}

In a test tube $2 \mathrm{~g}$. of sieved soil sample was placed with $5 \mathrm{ml}$ of $30 \%$ sodium hypochlorite $(\mathrm{NaOCl})$ solution (Soulsby, 1982). The tube was shaken intermittently. A few drops of prepared solution was placed on glass slide, placed cover glass and examined microscopically at $40 \times$ magnification, to identify the helminth's ovas on the basis of morphology described by (WHO, 1991 and Urquhart et al. 2001).

\section{Damp Pad Technique}

About $5 \mathrm{~g}$ of soil was placed in a test tube containing formal water, homogenized for one minute. The suspension was strained through wet cheese cloth placed over funnel to remove the coarse sand particles. Ether was added to the filtrate in a centrifuge tube and the mixture was centrifuged at 2,300 rpm for 3 minutes. The supernatant was decanted and the sediment placed on a clean slide, covered with a cover slip and examined microscopically (Nock et al. 2003). The ova / larvae of helminth parasites were identified with reference to Atlas of Parasitology (Seppo et al. 2002).

\section{Application Of Geographical Information System (GIS):}

The Geographical Information System (GIS) a digital data base management system (Guiqin et al., 2009) was applied to facilitate quick understanding, elaborated the research work, showed links between transmission and spatial distribution (Gorsevski et al. 2012). Window 2007, Arc GIS 9.2 and Arc view were used. Spatial data about slums of northern Lahore marked for research work was collected physically from the Solid Waste Management (SWM) and Geographical Information Department of Punjab Government (GIS).

\section{Application Of Thematic Disease Maps}

Spatial information, diagrammatical representation, geographical distribution and position of slums of northern Lahore and spatial distribution of observed Ancylostoma caninum's eggs in soil samples was organized 
by tabulating all data in Excel 2007 and then transferred to Arc GIS 9.2 and Arc view using various software of GIS to draw thematic disease maps to show several layers in a sequence.

\section{1 Ancylostoma Caninum's Eggs Shed By Dog In Soil Samples \\ IX. Results}

3600 soil samples were observed from the 6 slums (Bhutto Colony, Siddiqia Colony, Scheme No 2, Sheikhupura Road, Khairdin Park and Missri Shah) of Lahore, Punjab, Pakistan, from November 2006 to October 2008. A total of 3600 soil samples /area / 2 years were examined, showed $2.79 \%$ overall prevalence of A. caninum infestation (Table 1).

\section{Overall Prevalence}

An overall area wise prevalence (\%) of A. caninum's eggs in the soil showed prevalence $(3.22 \%)$ $(\mathrm{P}<0.001)$ in slums of Lahore, Punjab from November 2006 to October 2008 (Table 1).

\section{Area Wise Prevalence (\%)}

Area wise high prevalence of A. caninum's eggs in soil of six slums of Lahore, Punjab province was observed in Missri Shah (5\%) followed by Bhutto Colony (4.67\%), Siddiqia Colony (3.83 \%), Khairdin Park (2.83 \%), Sheikhupura Road (2\%) whereas lowest in Scheme No 2 (1\%) (Table 1; Fig. 1). Thematic disease Map 1 showed spatial distribution of eggs of A. caninum in contaminated soil samples of slums.

\section{Month Wise Prevalence (\%)}

After analyzing month wise data, highest prevalence $(10.67 \%)$ of was observed in October that gradually decreased to $(1 \%)$ in November followed by a decline to the lowest $(0.67 \%)$ in March of slums (Table 1; Fig 1). When statistical analysis (Z-test) was applied on month wise data, the prevalence (\%) of March was the lowest, so the month of March was compared with other months. No significant difference between prevalence (\%) of the month December, April, June, July and August was observed. Whereas November $(\mathrm{P}<0.001)$, September $(\mathrm{P}<0.001)$ and October $(\mathrm{P}<0.01)$ showed significant difference with respect to March (Table 1).

\section{Discussion}

In the present study soil samples analysis showed $3.22 \%$ overall prevalence. The outcomes of the present study are consistent with findings obtained from Wrocław collected from the parks, playgrounds, backyards and sandpits (Perec-Matysiak et al. 2008). Overall prevalence $20 \%$ was observed in Poland, these findings are contrary to the observation of the present study due to variation in used technique, locality, climatic conditions. Similarly in Nigeria 9\% prevalence of Ancylostoma spp including A. caninum was observed (Maikai et al. 2008) and $18.6 \%$ in Poland (Bojar and Klapec, 2012) contrary to the findings of the present study due to the difference in prevailing environmental conditions, SES and technique used. It was observed that soil contamination is increasing day by day due to increase population of stray dogs and immigrants from the country sides, residing in Kachiabadies "temporary shelters" with very low SES, inadequate sewage and sanitary system. Therefore it is the urgent need to eliminate the risk of infection in future by deworming the pet / stray dogs and national based control programme should be launched with provision of awareness, health education and proper living facilities. Thematic disease map has supported the findings of the present studied areas, also matched with the observations depicted by photographs. It is therefore necessary to improve the sewage, water system and give awareness to the inhabitants to improve their health and avoid throwing waste in open.

\section{Conclusion}

GIS was used to depict the spatial distribution. Ancylostomiasis is going to increase in human population due to increase in soil contamination as pet owners motivate their pet to defecate in parks/ surrounding areas of their residents and unaware about the biology of parasites. By improving the thematic disease map government could hit the infected pets or eliminate stray dogs to reduce the level of transmission of infection. 


\section{References}

[1] Ashraf, K., S., Rafique, H.A. Hashmi, A. Maqbool, and Z.I. Chaudhary (2008). Ancylostomiasis and its therapeutic control in dogs. J. Vet. Anim. Sci.1: 40-44.

[2] Avcioglu, H. and A. Burgu (2008). Seasonal prevalence of Toxocara ova in soil samples from public parks in Ankara, Turkey. Vect. Born. Zoonot. Dis., 8(3): 345-350.

[3] Bhatti, F.B., I. Hussain, and M .Z. Ali (2009). Adult B lymphoblastic leukaemia/lymphoma with hypodiploidy (-9) and a novel chromosomal translocation $\mathrm{t}(7 ; 12)(\mathrm{q} 22 ; \mathrm{p} 13)$ presenting with severe eosinophilia - case report and review of literature. J. Hematol. Oncol. 2: 26

[4] Bojar, H. and T. Kłapeć (2012). Contamination of soil with eggs of geohelminths in recreational areas in the Lublin region of Poland. Ann. Agric. Environ. Med. 19(2): 267-270.

[5] Cringoli, G., L. Rinaldi, M.P. Maurelli, M.E. Morgoglione, V. Musella, and J. Utzinger (2011). Ancylostoma caninum: calibration and comparison of diagnostic accuracy of flotation in tube, McMaster and FLOTAC in faecal samples of dogs. Exp. Parasitol. 128(1): 32-7.

[6] Edosomwan, E.U. and C.R. Chinweuba (2012). A survey on helminth parasites of dogs in Benin city, Edo State, Nigeria. J. Vet. Med. Animal H. 4(4): 56-60.

[7] Gorsevski, P.V., K.R. Donevska, C.D. Mitrovski, and J. P. Frizado (2012). Integrating multi-criteria evaluation techniques with geographic information systems for landfill site selection: A case study using ordered weighted average. Waste Management, 32: $287-296$.

[8] Guiqin, W., Q.L.L. Guoxue, and C. Lijun (2009). Landfill site selection using spatial information technologies and AHP: A case study in Beijing, China. J. Env. Man. 90: 2414-2421.

[9] Held, M.R., R.D. Bungiro, L.M. Harrison, I. Hamza, and M. Cappello (2006). Dietary iron content mediates hookworm pathogenesis in vivo. Infect. Immune. 74(1): 289-295

[10] Isabel, G.M., G.N. Lizeth, and C.J., Carlos (2005). Prevalence of intestinal helminths in dogs from Quindío Province. Biomédica. 25(3):346-352.

[11] Jaffry, K.T., S. Ali, A. Rasool, A. Raza, and Z.J. Gill (2009). Risk Mapping for Avian Influenza: a Social-Ecological Problem. Int. J. Agri. Bio. 15(3): 32

[12] Khayatnouri, M.H. and Garedaghi (2012). Efficacy of Ivermectin Pour- on administration against natural Ancylostoma caninum infeststion in native dogs of East-Azerbiajan Province, Iran. J. Animal Vet. Adv. 11(4): 526-530.

[13] Kollataj, W., A. Milczak, B. Kollataj, I.D. Karwat, M. Sygit and K. Sygit (2012). Risk factors for the spread of parasitic zoonoses among dog owners and their families in rural areas. Ann. Agri. Env. Med. 19(1): 79-84.

[14] Kurnosova, O.P. (2009). Parasitic diseases in domestic dogs and cats in the megalopolis of Moscow. Med. Parazitol. (4): $31-5$.

[15] Lamb, J., M. Napier and S. Mukaratirwa (2012). PCR-based identification reveals unique Southern African internal transcribed spacer (ITS) haplotypes of hookworms (Ancylostoma) of dogs from the Durban metropole, South Africa. Afr. J. Biotechnology, 11(8): 2099-2106

[16] Loukas A. and P. Prociv (2001). Immune responses in hookworm infections. Clin. Microbiol. Rev. 14: 689-703.

[17] Loukas, A., J. Bethony, S. Brooker, and P. Hotez (2006). Hookworm vaccines: past, present, and future. Lancet Infect. Dis. 6: 73341.

[18] Mahdy, M.A., Y.A. Lim, R. Ngui, M.R. Siti Fatimah, S.H. Choy, N.J. Yap, H.M. Al-Mekhlafi, J. Ibrahim, and J. Surin (2012). Prevalence and zoonotic potential of canine hookworms in Malaysia. Parasit. Vectors. 7(5): 88

[19] Maikai, B.V., J.U. Umoh, O.J. Ajanusi, and I. Ajogi, (2008). Public health implications of soil contaminated with helminth eggs in the metropolis of Kaduna, Nigeria. J. of Helminthol. 82(2): 113-118.

[20] Martin, U.O. and M.U. Demonte (2008). Central region of Argentina, Urban contamination with zoonotic parasites in the central region of Argentina. Medicina. 68: 363-366.

[21] Nock, I.H., N. Duniya, and M. Galadima (2003). Geohelminth eggs in the soil and stool of pupils ofsome primary schools in Samaru, Zaria Nigeria. The Nig. J. Parasitiol.,24: 115-122.

[22] Perec-Matysiak, A., J. Hildebrand, G. Zaleśny, A. Okulewicz, A. Fatuła (2008). The evaluation of soil contamination with geohelminth eggs in the area of Wrocław, Poland. Wiad Parazytol., 54(4): 319-23.

[23] Razmi, G.R., K. Sardari, and A.R., Kamrani (2006). Prevalence of Echinococcus granulosus and other intestinal helminths of stray dogs in Mashhad area, Iran. Archives of Razi Institute, 61(3): 143-148.

[24] Seppo, T.R, A.G. Regina, R. Edgar, and L.T. Glickman (2002). Prevalence and risk factors for protozosan and Nematode infections of children in Santa Anna, Ecuador Publication for health education programme planning. Medicine.,18: 15-20.

[25] Soulsby, E.J.L. (1982). Helminths arthropods and protozoa of domesticated animals. Bailliere Tindall, London, pp. 809.

[26] Sowemimo, D.A. and S.O. Asaolu (2008). Epidemiology of intestinal of intestinal helminth parasites of dogs in Ibadan, Nigeria. J. Helminthol., 82: 89-93.

[27] Ugwoke, E V., P.A. Audu, J.U. Umoh and J.A. Adakole (2011). Prevalence of intestinal helminthes of dogs that have been disposed off at non-descript abattoirs in Zaria, Nigeria. Bayero J. Pure Appl. Sci., 4(1): 44 - 47.

[28] Umar, Y.A. (2009). Intestinal helminthoses in dogs in kaduna metropolis, Kaduna State, Nigeria. Iranian J. Parasitol., 4(1): 34-39.

[29] Urquhart, G.M., J. Armour, J.L. Duncan, A.M. Dunn, and F.W. Jennings (2001). Veterinary Parasitology, Ed. Elbs Langman, U.K.Yamaguti, S., 1975. A Synoptical Review Of Life Historics Of Digenetic Trematode Of Vertebrates With Special Reference To The Morphology Of Their Larvae. Keiguku Publ. Co., Tokyo. Pp. 410-413.

[30] World Health Organization (1991). Basic laboratory methods in medical parasitology. pp. 25-28. 
TABLE 1: Overall areawise, monthwise and seasonwise prevalence (\%) of Ancylostoma caninum's eggs shed by dogs in soil samples of slums of Lahore, Punjab, Pakistan from November 2006- October 2008.

\begin{tabular}{|c|c|c|c|c|}
\hline \multirow{2}{*}{$\underset{\tilde{E}}{\tilde{E}}$} & \multicolumn{3}{|c|}{ Total $\mathbf{n = 3 6 0 0}$} & \multirow[b]{2}{*}{ Prevalence $(\% \pm$ S.E $)$} \\
\hline & Slums & Obser-ved & Infect-ed & \\
\hline \multirow{6}{*}{ 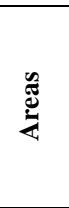 } & Bhutto Colony & \multirow{6}{*}{ 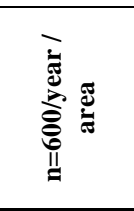 } & 28 & $4.67 \pm 0.86 * * *$ \\
\hline & Siddiquia Colony & & 23 & $3.83 \pm 0.78 * *$ \\
\hline & Scheme No. 2 & & 6 & $1.00 \pm 0.41$ \\
\hline & Sheikhupura Road & & 12 & $2.00 \pm 0.57$ \\
\hline & Khairdin Park & & 17 & $2.83 \pm 0.68$ \\
\hline & Missri Shah & & 30 & $5.00 \pm 0.89 * *$ \\
\hline & Total & 3600 & 116 & $3.22 \pm 0.29$ \\
\hline \multirow{12}{*}{ 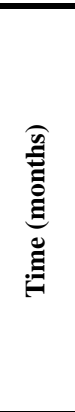 } & Nov2006\&2007 & \multirow{12}{*}{ 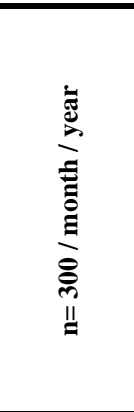 } & 3 & $1.00 \pm 0.57$ \\
\hline & Dec $2006 \& 2007$ & & 5 & $1.67 \pm 0.74$ \\
\hline & Jan $2007 \& 2008$ & & 7 & $2.33 \pm 0.87$ \\
\hline & Feb 2007\&2008 & & 7 & $2.33 \pm 0.87$ \\
\hline & Mar 2007\&2008 & & 2 & $0.67 \pm 0.47 *$ \\
\hline & Apr 2007\&2008 & & 3 & $1.00 \pm 0.57$ \\
\hline & May $2007 \& 008$ & & 11 & $3.67 \pm 1.09$ \\
\hline & Jun $2007 \& 2008$ & & 9 & $3.00 \pm 0.98$ \\
\hline & Jul 2007\&2008 & & 8 & $2.67 \pm 0.93$ \\
\hline & Aug 2007\&008 & & 11 & $3.67 \pm 1.09$ \\
\hline & Sep 2007\&2008 & & 18 & $6.00 \pm 1.37$ \\
\hline & Oct $2007 \& 2008$ & & 32 & $10.67 \pm 1.78^{* * *}$ \\
\hline \multirow{5}{*}{ 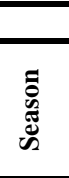 } & Total & 3600 & 116 & $3.22 \pm 0.29$ \\
\hline & Winter & 1200 & 22 & $1.83 \pm 0.39$ \\
\hline & Spring & 600 & 5 & $0.83 \pm 0.37 * * *$ \\
\hline & Summer & 1200 & 39 & $3.25 \pm 0.51 * * *$ \\
\hline & Autumn & 600 & 50 & $8.33 \pm 1.13$ \\
\hline \multicolumn{5}{|c|}{ Overall prevelance $(\%)($ Slums+Urban) } \\
\hline
\end{tabular}

$* \mathbf{P}<.05, * * \mathbf{P}<.01, * * * \mathbf{P}<.001 \mathrm{Z}$-test

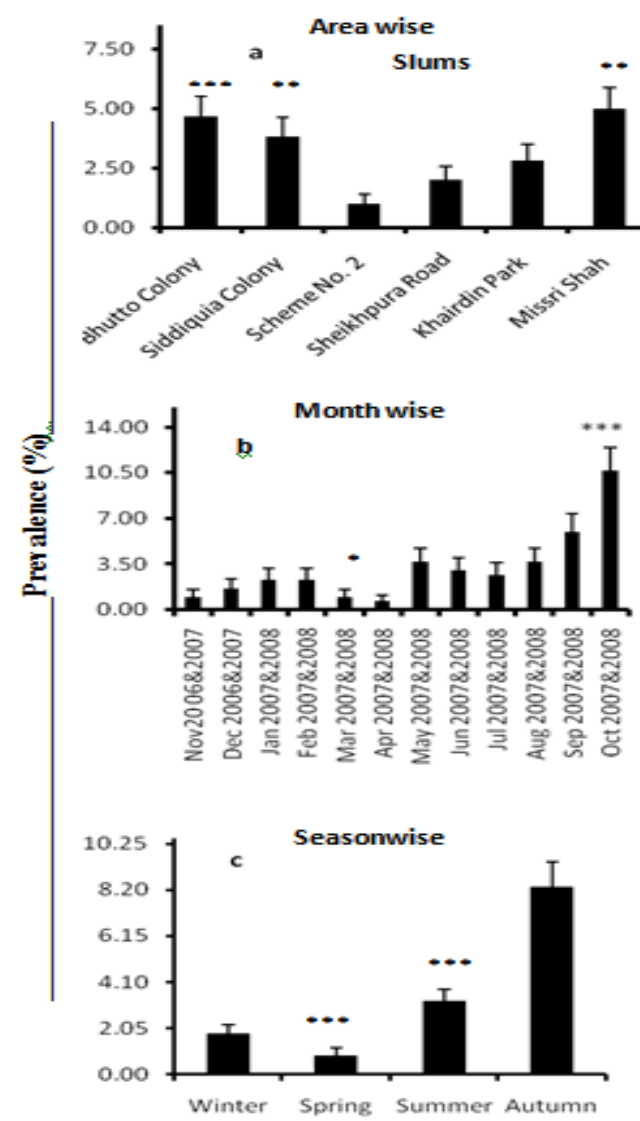

Fig. 1: Prevalence (\%) of Ancylostoma caninum's eggs shed by dogs in soil samples of slums (a) area wise (b) month wise and (c) season wise of Lahore from Nov 2006- Oct 2008. Z-test * $=\mathrm{P}<0.05, * *=\mathrm{P}<0.01, * * * \mathrm{P}<.001$. 


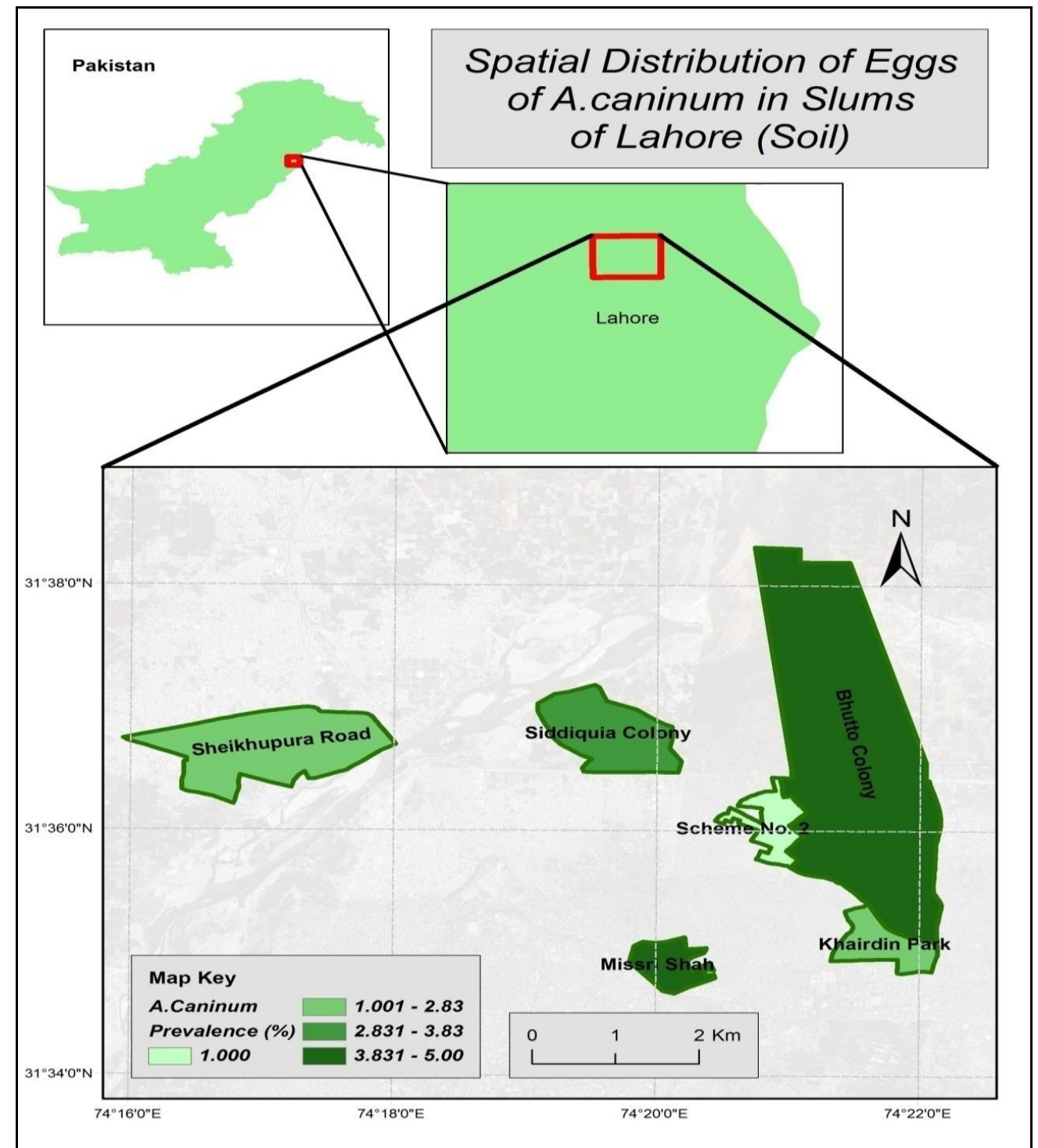

Fig. 2: Thematic disease map 1: Spatial distribution of eggs of Ancylostoma caninum (soil) in slums of Northern-Lahore from Nov.2008 to Oct.2009 